\title{
Bankacılık Sektöründe Rekabet ile Mali Sağlamlık Arasındaki ìlişkinin İncelenmesi: Gelişmekte Olan Ülkeler için Panel ARDL Modeli
}

Kemal Eyüboğlư ${ }^{1}$ Sinem Eyüboğlu²

Bankacılık Sektöründe Rekabet ile Mali Sağlamlık Arasındaki İlişkinin İncelenmesi: Gelişmekte Olan Ülkeler için Panel ARDL Modeli

Öz

Rekabet, çoğu sektörde verimliliği arttırdığı ve yeniliği teşvik ettiği için genellikle itici bir güç olarak kabul edilmektedir. Finans sektöründe de ülkeler rekabeti arttırıcı reformlar gerçekleştirmektedir. Bu çalışmada, 1996-2015 dönemi için 16 gelişmekte olan ülke bankacılık sektöründe, Panel ARDL havuzlanmış ortalama grup (PMG) tahmincisi kullanılarak, rekabet ile mali sağlamlık arasındaki ilişkinin incelenmesi amaçlanmıştır. Sonuçlar, rekabetin ve mali sağlamlığın hem uzun dönemde hem de kısa dönemde birlikte hareket ettiğini ortaya koymuştur. Ayrıca rekabetin uzun ve kısa dönemde finansal sağlamlık üzerinde negatif bir etkisi olduğu tespit edilmiştir. Elde edilen bulgular gelişmekte olan ülke bankacilık sektörlerinde "rekabet-kırılganlık" görüşünü destekler niteliktedir.

Anahtar Kelimeler: Finansal sağlamlık, rekabet, Panel ARDL modeli, Z-skoru
Testing the Relationship between Competition and Soundness in Banking Sector: Panel ARDL Model in Emerging Countries

Abstract

Competition is generally considered as a positive driving force in many sectors as it enhances efficiency and promotes innovation. In the financial sector, countries are implementing reforms that increase competition. This study aims to examine the relationship between competition and financial soundness employing Panel ARDL pooled mean group (PMG) estimations in 16 emerging countries' banking sectors for 1996-2015 periods. Results show that competition and financial soundness are moving together in the short and long-run. Also, it is found that competition has a negative effect on financial soundness in the short and long-run. Findings tend to support "competition-fragility" approach in emerging country banking sectors.

Keywords: Financial soundness, competition, Panel ARDL model, Z-score

\section{Giriş}

Bankacılık sektörü, tasarruf sahipleri ile fon ihtiyacı olanlar arasındaki temel finansal aracı olduğundan, ekonomik büyümede önemli bir rol oynamaktadır. Bu anlamda, bankaların aracılık işlemlerini daha yüksek refah elde etmek için mümkün olan en düşük maliyetle gerçekleştirebilmesi oldukça önemlidir. Bankaların faiz marjı ne kadar düşük olursa, mali aracılık maliyetleri de o kadar düşük olacaktır (Maudos ve Guevara, 2004: 2260).

Rekabet çoğu sektör için genellikle verimliliği ve tedarik kalitesini arttıran, yeniliği teşvik eden pozitif bir etken olarak kabul edilir. Ancak bankacılık sektöründe rekabetin etkisi açısından literatürde farklı görüşler yer almaktadır. Rekabet-kırılganlık görüşü, bankacılık sektöründeki yüksek rekabetin, bankaların finansal istikrarsızlığını ve kırılganlığını artırabileceği fikrini savunmaktadır. Son derece rekabetçi bir bankacılık sektöründe banka yöneticileri, kar amaçlarını yerine getirebilmek için yüksek riskli operasyonları hayata geçirmeye istekli

${ }^{1}$ Doç. Dr., Karadeniz Teknik Üniversitesi, ỉktisadi ve İdari Bilimler Fakültesi, İşletme Bölümü, keyuboglu@msn.com, yazar ORCID bilgisi: orcid.org/0000-0002-2108-9732.

${ }^{2}$ Dr., Avrasya Üniversitesi, iktisadi ve İdari Bilimler Fakültesi, iktisat Bölümü, sinemyilmaz17@ hotmail.com, yazar ORCID bilgisi: orcid.org/0000-0002-3525-9173. 
olabilmektedir. Bu durum ise finansal sıkıntı nedeniyle iflas ile sonuçlanabilecek daha riskli varlık portföylerinin oluşturulmasına imkan verebilmektedir. Diğer bir ifade ile rekabetkırılganlık görüşüne göre rekabet, bankaların piyasa güçlerini aşındırmakta, kar marjlarını azaltmakta ve piyasa değerlerini düşürmektedir. Bu durum ise, eski karlarını korumak için bankaları daha riskli politikalar izlemeye teşvik edebilmektedir (Keeley, 1990; Demsetz vd., 1996; Berger vd., 2009). Riskli politikalara örnek olarak kredi portföyünde daha fazla kredi riski alınması ve sermaye düzeyinin düşürülmesi örnek olarak gösterilebilir. Daha riskli olan bu politikalar, takipteki kredi oranlarını arttırabilmekte ve banka iflasına yol açabilmektedir (Jimenez vd., 2013: 185). Örneğin, Keeley (1990) 1980'lerde ABD'de artan rekabetin banka başarısızlıklarının artmasına neden olduğunu ifade etmiştir. Diğer taraftan, bankaların daha az agresif operasyonal süreçler yürütecekleri daha az rekabetçi bir ortamda, daha fazla risk için istek azalmakta ve bankacılık sektörünün istikrarı artmaktadır (Cuestas vd., 2017: 3).

Öte yandan bankacılık literatüründe rekabetin, bankaların kaynaklarını daha verimli kullanmasını, inceleme ile denetleme mekanizmasının daha etkin olmasını sağladığını savunulmaktadır. Aynı zamanda takipteki kredilerden zarar görme olasılığının daha düşük olduğu da ifade edilmektedir (Petersen ve Rajan, 1995; Williams, 2004). Bunun aksine, rekabetçi olmayan piyasalarda banka yöneticilerinin sorunlardan kaçmasına imkan tanınmakta; bu sayede maliyetler kontrol altına alınamamakta ve böylece bankalar düşük verimlilik ile çalışmaktadır (Pagano, 1993; Berger ve Hannan, 1998).

Rekabet-istikrar görüşü ise, banka sayısının az olduğu yüksek piyasa gücüne sahip bankacılık piyasasında, bankaların kredi faiz oranlarından daha fazla kar marjı yaratmayı istemesi nedeniyle banka portföyü risklerini artırabileceğini öne sürmektedir. Bu durumda, müşterilerin borçlanma için daha yüksek bir maliyet ödemesi gerekir, bu da takipteki kredilerin artış olasılığını yükseltebilir (Boyd ve De Nicoló, 2005; Beck vd., 2013). Bu noktaya bağlı olarak, yüksek rekabet sermayenin maliyeti üzerinde etkiye sahip olabilir ve şirketler ile bireyler daha düşük faiz oranlarına erişebilir, yatırım projelerinin karlılığı arttırabilir, kredi risklerini azaltabilir ve nihayetinde finansal istikrarın oluşumuna katkıda bulunabilir (Cuestas vd., 2017: 3).

Demsetz (1973) tarafından önerilen etkin yapı hipotezinden uyarlanan "rekabet-etkinlik" görüşüne göre ise rekabetteki artış, bankaları maliyetleri en aza indirmeye ve daha düşük fiyatlarla hizmet sunmaya zorlamakta, buna bağı olarak karlııkta artış sağlanmaktadır. Chen (2007) rekabetçi bankaların süreçleri daha iyi tarama ve izleme imkanlarının olduğunu ve bu nedenle de takipteki kredilerden sıkıntı yaşama olasılıklarının daha düşük olduğunu ifade etmiştir. Aynı şekilde Wheelock ve Wilson (1995), Berger ve DeYoung (1997), Kwan ve Eisenbeis (1997) ile Williams (2004) mali açıdan sıkıntı çeken bankalarda verimsizliğin çok yüksek düzeylerde olduğuna dair bulgulara ulaşmışlardır. Padoa-Schioppa (2001) ise rekabet ortamında bankacılık sisteminin şoklara karşı daha güçlü ve daha dayanıklı olacağını belirtmiştir.

Bu çalışmada 1996-2015 dönemi için 16 gelişmekte olan ülke bankacılık sektöründe rekabet ile mali sağlamlık arasındaki uzun ve kısa dönemli ilişkinin Panel ARDL modeli ile incelenmesi amaçlanmıştır. Genel olarak çalışmanın, bankacılık düzenlemeleri ve birleşme ile devralmaların değerlendirilmesi için politika yapıcılara ve denetleyici kurumlara yararlı bilgiler sunacağı düşünülmektedir. 


\section{Literatür İncelemesi}

Rekabet ve sağlamlık arasındaki ilişkiyi inceleyen çalışmalarda farklı sonuçlara ulaşılmıştır. Bankacılıkta rekabet ve sağlamlık arasındaki ilişkinin incelenmesi Keeley'in (1990) çalışması ile başlamıştır. Keeley çalışmasında ABD'de 1980'lerde artan rekabetin kâr marjlarını azalttığını ve bankaların getirileri arttırmak için aşırı riskler alabildiğini ve bunun banka iflaslarında artışa neden olduğunu ifade etmiştir. Besanko ve Thakor (1993) bankacılıkta artan rekabetin, bankaların daha fazla risk almasına yol açtığını ifade etmişlerdir. Demsetz vd. (1996) 1986-1994 dönemi için $A B D^{\prime}$ de franchise değeri ile risk alma arasındaki ilişkiyi araştırmıştır. Elde edilen bulgular daha fazla piyasa gücüne sahip ABD bankalarının aynı zamanda en yüksek ödeme gücü oranlarına ve daha düşük seviyede varlık riskine sahip olduklarını göstermiştir.

Salas ve Saurina (2003) 1969-1992 dönemi için İspanya'da bankacılıkta yapılan yasal değişikliklerin İspanyol bankalarının piyasa gücü üzerindeki etkilerini incelemişlerdir. Çalışmada sonuç olarak, yüksek piyasa gücünün İspanyol bankalarının borç ödeme kabiliyetini arttırdığı ve takipteki kredi oranlarını düşürdüğü ortaya konmuştur. Repullo (2004) ise İspanya'da rekabetin yasal boşlukların olmasının bankaların daha fazla risk almasına yol açtığını ifade etmiştir. Maudos ve Guevara (2004) 1993-2000 dönemi için Avrupa bankacılık sektörlerinde (Almanya, Fransa, İngiltere, İtalya ve İspanya) faiz marjını etkileyen faktörleri analiz etmişlerdir. Sonuçlar Avrupa bankacılık sistemindeki marjların düşüşünün rekabet koşullarının gevşetilmesi ile ilişkili olduğunu göstermiştir. Bofondi ve Gobbi (2004) 1986-1996 yılları için italya'da 729 bankayı dikkate alarak temerrüt oranını etkileyen faktörleri incelemiş ve kredi temerrüt oranının piyasadaki bankaların sayısı arttıkça yükseldiğini vurgulamışlardır.

Schaeck vd. (2006) 1980-2003 dönemini dikkate alarak 38 ülkede rekabet ile kırılganlık arasındaki ilişkiyi test etmişlerdir. Yapılan analizler daha rekabetçi bankacılık sistemlerinin krizlere daha az eğilimli olduğunu ortaya koymuştur. Yeyati ve Micco (2007) 1993-2002 yılları arasında Arjantin, Brezilya, Şili, Kolombiya, Kosta Rika, El Salvador, Meksika ve Peru'da 1990'larda bankaların rekabetçi davranışlarını etkileyen faktörleri incelemişlerdir. Sonuç olarak artan yoğunlaşmanın, bankacılık rekabetini zayıflatmadığı ancak artan yabancı nüfuzun daha az rekabetçi bir sektöre yol açtığı vurgulanmıştır. Ayrıca, 8 Latin Amerika ülkesinde banka rekabeti arttıkça banka riskinin de arttığı ifade edilmiştir.

Schaeck ve Cihak (2008) 1995-2005 dönemi için Avrupa'da ve ABD'de rekabet ile finansal sağlamlık arasındaki ilişkiyi incelemişlerdir. Elde edilen bulgular Avrupa için artan rekabetin banka sağlamlığını verimlilik aracılığıyla artırdığını göstermiştir. ABD için ise rekabetin verimlilikten olumlu bir şekilde etkilendiği ortaya konmuştur. Casu ve Girardone (2009) 20002005 yılları arasında Fransa, Almanya, İtalya, İspanya ve Birleşik Krallık'ta faaliyet gösteren 2701 ticari bankayı ele alarak rekabet ve verimlilik arasındaki nedensellik ilişkisini araştırmışlardır. Elde edilen bulgular piyasa gücü ve verimlilik arasında pozitif bir nedensellik olduğunu ortaya koyarken, verimlilikten rekabete doğru nedenselliğin zayıf olduğunu da göstermiştir.

Turk (2010) 1999-2005 dönemi için Afrika, Doğu/Güney Asya ve Pasifik, Doğu Avrupa ve Orta Asya, Latin Amerika ve Karayipler ve Orta Doğu gibi farklı bölgelerdeki 60 gelişmekte olan ülke ticari bankalarında piyasa gücünün banka verimliliğini ve istikrarını nasıl etkilediğini incelemişlerdir. Sonuçlar, piyasa gücünün derecesindeki artışın, önemli maliyet verimliliği kayıplarına rağmen, daha fazla banka istikrarına ve kâr verimliliğine yol açtığını göstermektedir. Fu vd. (2014) 2003-2010 dönemi itibariyle 14 Asya Pasifik ülkesi için bankacılık sektöründe rekabet ile mali istikrar arasındaki ilişkiyi incelemişlerdir. Sonuçlar, daha fazla yoğunlaşmanın finansal kırılganlığı arttırdığını ve düşük fiyatlama gücünün de çeşitli makroekonomik, bankaya 
özgü, düzenleyici ve kurumsal faktörleri kontrol ettikten sonra banka riskine maruz kalmaya yol açtığını göstermiştir. Dima vd. (2014) 1997-2010 yılları için 63 ülkeyi ele alarak bankaların sağlamlığı, bankacılık sektörünün yapısal özellikleri ve verimlilik arasındaki ilişkiyi incelemişlerdir. Sonuçta verimliliğin sağlamlık üzerinde etkisi olduğunu ifade etmişlerdir.

Arrawatia vd. (2015) rekabet ve verimlilik arasındaki ilişkiyi Hint bankaları açısından 19962011 dönemi için ele almışlardır. Sonuçlar rekabetin verimliliği olumlu yönde etkilediğini göstermiştir. Apriadi vd. (2016) 2005-2013 dönemi için Endonezya'da rekabet ve bankacılık kırılganlığı arasındaki ilişkiyi test etmişlerdir. Çalışmanın sonuçları, rekabetin bankacılık verimliliğinin yanı sıra bankacılık istikrarını azaltacağını, verimliliğin ise her iki yönde de istikrar ile pozitif yönde ilişkili olduğunu ortaya koymuştur.

Apergis ve Polemis (2016) 1997-2011 yılları arasında Orta Doğu ve Kuzey Afrika ülkeleri için bankacılık sektöründe rekabet ve verimlilik arasındaki ilişkiyi incelemişlerdir. Sonuçlar, verimlilikten rekabete doğru tek yönlü Granger nedenselliğin olduğunu göstermiştir. Cuestas vd. (2017) 2000-2014 döneminde Baltık ülkelerinde (Estonya, Letonya ve Litvanya) bulunan ticari bankalarda rekabet ve banka riski arasındaki ilişkiyi değerlendirmişlerdir. Yapılan analizler sonucu elde edilen bulgular, daha yüksek bir piyasa gücünün (yani düşük bir rekabet ortamının) banka riski alma ve banka iflas riskiyle ilişkili olduğunu ortaya koymuştur.

Leroy ve Lucotte (2017) Avrupa bankacılık sistemi için 2004-2013 dönemini ele alarak rekabet ile finansal istikrar arasındaki ilişkiyi incelemişlerdir. Çalışma sonucunda yüksek rekabet ortamının banka riskini ve kırılganlı̆̆ını arttırdığını saptamışlardır. Kouki ve Al-Nasser (2017) 2005-2010 dönemi için Afrika'da piyasa gücünün banka verimliliği ve istikrarı üzerindeki etkilerini incelemiş ve yüksek pazar gücünün yüksek verimlilik ile karlılık sağladığını ortaya koymuştur.

Türkiye'de yapılan çalışmalarda ise Abbasoğlu vd. (2007) yoğunlaşma ve rekabet arasındaki ilişkiyi 1995-2005 yılları için ele almışlardır. Sonuç olarak yoğunlaşma ile rekabet arasında istatistiksel açıdan anlamlı bir ilişki olmadığı belirlenmiştir. Tunay (2009) 1988-2007 dönemi için Türk bankacılık sektöründe rekabet ile kırılganlık ilişkisini incelemiş ve yapılan analizler sonucunda kırılganlık ve yoğunlaşma arasında pozitif yönlü bir ilişki olduğu saptanmıştır. Yaldız ve Bazzana (2010) piyasa gücünün kredi ve banka riskleri üzerindeki etkisini 2001-2009 yılları için analiz etmişlerdir. Çalışma sonucunda 2000 yılından sonraki yoğun düzenlemelerin banka sayısında önemli bir düşüşe neden olduğu ve böylece rekabeti azalttığı ifade edilmiştir.

Yağcılar (2011) ise 1992-2008 dönemini dikkate alarak bankacılık sektöründe kârlılık ve pazar payı ile rekabet gücü arasında anlamlı ve negatif bir ilişki olduğu sonucuna ulaşmıştır. İskenderoğlu ve Tomak (2013) 2002-2012 dönemi için 15 özel ticari bankayı dikkate alarak yoğunlaşma ve rekabet arasındaki ilişkiyi incelemiş ve seriler arasında anlamlı bir ilişki olmadığı sonucuna ulaşmıştır.

Taşkın (2014) 2003-2013 yılları arasını dikkate alarak yapmış olduğu çalışma sonucunda finansal istikrarın artması durumunda kısa ve uzun dönemde rekabetin azaldığını vurgulamıştır. Özcan ve Çiftçi (2015) 2006-2013 dönemi için mevduat bankacılığında yoğunlaşma ile kârlılık arasındaki ilişkiyi incelemişlerdir. Yapılan analizler sonucunda piyasa payı ve kârlılık arasında pozitif bir ilişki olduğu belirlenmiştir. Bunun yanı sıra sonuçlar mevduat bankacılığında rekabetin yüksek olduğunu ve ayrıca rekabetin kârlılığın önemli belirleyicilerinden biri olduğunu göstermiştir. 
Korkmaz vd. (2016) 2007-2014 dönemi için finansal kırılganlık ve yoğunlaşma ilişkisini analiz etmişlerdir. Yapılan nedensellik analizi sonucunda, Türkiye'de bankacılık sektöründe yoğunlaşma ile finansal kırılganlık arasında çift yönlü bir ilişki olduğu belirlenmiştir. Kasman ve Kasman (2016) Türk bankacılık sektöründe 2002-2012 dönemini dikkate alarak banka büyüklüğünün ve rekabetin, kazanç volatilitesi ve iflas riski üzerindeki etkisini araştırmışlardır. Sonuç olarak banka büyüklüğü ile kazanç oynaklığının negatif yönde ilişkili olduğu, diğer bir ifade ile büyük bankaların daha az riskli olduğu saptanmıştır. Illaveten banka büyüklüğü ile iflas riski arasında pozitif ilişki olduğu bulunmuştur.

\section{Veri Seti ve Yöntem}

Çalışmada 16 gelişmekte olan ülke için 1996-2015 dönemi itibariyle bankacılık sektöründe rekabet ile mali sağlamlık arasındaki ilişki incelenmiştir. Tablo 1'de çalışmada yer alan ülkeler gösterilmiştir. Çalışmada bankacılık sektörünün rekabet yapısının belirlenmesi için Lerner Endeksi'nden, mali sağlamlık düzeyinin belirlenmesi için Z-Skoru'ndan yararlanılmıştır. Lerner Endeksi ve Z-Skoru verileri Dünya Bankası'nın Global Financial Development Database'inden alınmıştır.

Tablo 1: Çalışmada Yer Alan Gelişmekte Olan Ülkeler

\begin{tabular}{cccc}
\hline Arjantin & Kolombiya & Endonezya & Peru \\
Brezilya & Hırvatistan & Ürdün & Polonya \\
Şili & Macaristan & Litvanya & Romanya \\
Türkiye & Hindistan & Paraguay & Rusya \\
\hline
\end{tabular}

Bankacılık sektöründeki rekabet derecesinin bir göstergesi olarak Lerner endeksi literatürde sıklıkla kullanılmaktadır (Prescott ve McCall, 1975; Shaffer, 1993; Angelini ve Cetorelli, 1999; Arranwatia vd., 2014; Cuestas vd., 2017). Lerner endeksi; bankacılık sektöründeki piyasa gücünün bir ölçüsü olmakla birlikte çıktı fiyatlandırması ve çıktı fiyatları ile marjinal maliyetler arasındaki fark olarak tanımlanmaktadır. Lerner endeksindeki artış, sektördeki rekabetin azaldığını göstermektedir. Endeks değerleri 0 ile 1 arasında değerler almakta; 0 tam rekabeti, 1 ise tekel durumunu ifade etmektedir.

Z-skoru ise ülkenin ticari bankacılık sisteminin iflas riskini ölçmektedir. Z-skoru literatürde oldukça popülerdir (örneğin, Mercieca vd., 2007; Kasman ve Kasman, 2016; Demirgüç-Kunt vd., 2006; Apriadi vd., 2016, Cuestas vd., 2017). Yüksek Z-skoru, düşük iflas olasılığı anlamına gelmektedir.

Panel verileriyle çalışırken, yatay-kesit bağımlılığı nedeniyle yanlı sonuçlar elde edilebileceğinden seriler arasındaki ilişkiyi incelemeden önce yatay-kesitsel bağımlılık olup olmadığını test etmek oldukça önemlidir. Kesitsel bağımlılığı test etmek için Breusch-Pagan (1980) LM, Pesaran (2004) scaled LM, Baltagi vd. (2012) bias-corrected scaled LM ve Pesaran (2004) CD testleri kullanılmıştır. Çalışmada mali sağlamlık ile rekabet arasındaki kısa ve uzun dönemli ilişkiler Pesaran vd. (1999) tarafından geliştirilen Panel ARDL-PMG ${ }^{3}$ yaklaşımı ile araştırılmıştır. Maksimum olabilirlik yöntemine dayanan bu yaklaşım, en tutarlı yaklaşım olarak kabul edilir çünkü bireysel özellikleri (ülke, bölge, vb.) dikkate alır ve uzun dönemli ilişkinin sağlam bir değerlendirmesini yapar. Ayrıca PMG yaklaşımı, kısa dönemli katsayıların

\footnotetext{
3 Panel ARDL'nin üç çeşidi vardır. Bunlar ortalama grup (MG), havuzlanmış ortalama grup (PMG) ve dinamik sabit etki (DFE) yaklaşımlarıdır ve hepsi maksimum olasılık tahminleri (MLE) altında çalışır. Çalışmada Hausman testi, PMG'nin MG ve DFE tahminlerinden daha tutarlı olduğunu gösterdiğinden sadece PMG yaklaşımı açılanmıştır.
} 
heterojenliğini kabul ederken, uzun dönemli katsayıların paneldeki tüm birimler için aynı ve homojen olduğunu varsaymaktadır (Attiaoui, 2017: 13039).

Panel ARDL-PMG yaklaşımının kullanılabilmesi için serilerin seviyesinde veya farkında durağan olması gerekmektedir. Dolayısıyla serilerin birim kök özelliklerinin incelenmesi gerekmektedir. Çalışmada serilerin durağan oldukları seviyeler hem birinci nesil (LLC ve IPS) hem de yatay kesit bağımlılığı olabileceğinden ikinci nesil birim kök testleri (CADF) ile incelenmiştir.

ARDL modeli kısa ve uzun dönemli ilişkilerin araştırılmasına imkan sağlamaktadır. Bu yaklaşım, serilerin durağan oldukları seviyelere bakmaksızın (I(2) hariç) uzun dönemli ilişkileri test edebildiği için diğer yöntemlere göre avantaj sağlamaktadır. Buna ek olarak, yöntem, hem içsel hem de dışsal değişkenler için gecikme uzunluğu dahil ederek, içsellikten kaynaklanan problemleri ortadan kaldırmakta ve tutarlı tahminler sunmaktadır. Pesaran vd.'ye göre (1999), değişkenler arasındaki uzun dönemli ilişkiyi içeren ARDL $(p, q)$ modeli şu şekilde yazılabilir:

$$
\Delta Y_{1, i t}=\alpha_{1 i}+\gamma_{1 i} Y_{1, i t-1}+\sum_{l=2}^{k} \gamma_{1 i} X_{1, i t-1}+\sum_{j=1}^{p-1} \delta_{1 i j} \Delta Y_{1, i t-j}+\sum_{j=0}^{q-1} \sum_{l=2}^{k} \delta_{1 i j} \Delta X_{1, i t-j}+\varepsilon_{1, i t}
$$

Burada $Y$ bağımlı değişkeni, $X$ bağımsız değişkeni, I seri sayısını, $\varepsilon_{\text {it }}$ hata terimini ve $\Delta$ fark operatörünü ifade etmektedir. Uygun gecikme uzunluğu ise AIC kriterine göre belirlenmiştir.

Panel ARDL-PMG'nin kullanılabilmesi için değişkenlerin eşbütünleşik olması gerekmektedir. Panel ARDL yönteminde değişkenler arasındaki olası uzun dönemli ilişkilerin varlığını test etmek için literatürde genellikle Pedroni (1999) ve Kao (1999) eşbütünleşme testleri kullanılmaktadır (Chirwa ve Odhiambo, 2018; Asongu vd., 2016; Boubaker ve Jouini, 2014; Bildirici ve Kayıkçı, 2013). Bu çalışmada değişkenler arasındaki uzun dönemli ilişkinin var olup olmadığı Pedroni (1999) eşbütünleşme testi ile araştırılmıştır. Pedroni (1999) tarafından geliştirilen eşbütünleşme testi, aşağıdaki (2) numaralı panel regresyonundan hareketle ifade edilmektedir:

$y_{i t}=\alpha_{i t}+\delta_{i t} t+X_{i t} \beta_{i}+e_{i t}$

(2) numaralı eşitlikte yer alan $y_{\text {it }}$ ve $X_{\text {it }}$ sırasıyla $\left(N^{*} T\right) \times 1$ ve $\left(N^{*} T\right)^{x} m$ boyutundaki gözlemlenebilen değişkenleri vurgulamaktadır. Bu test, panel serilerinde eşbütünleşik bir ilişkinin olmadığını sınayan sıfır hipotezinin asimptotik ve sonlu gözlem özellikleri üzerine inşa edilmiştir (Ağırman vd., 2014: 109).

ilk grubu oluşturan testler, boyutlar-içi yaklaşımı üzerine temellendirilmiş olup; panel vistatistiği, panel $p$-istatistiği, panel PP-istatistiği ve panel ADF-istatistiği olmak üzere dört testten oluşmaktadır. Bu istatistikler, tahmin edilen kalıntı serileri üzerindeki birim kök testleri için farklı yatay kesit birimleri arasında otoregresif katsayıları birleştirmektedir. ikinci grubu oluşturan testler ise boyutlar-arası yaklaşıma dayanmakta ve üç testten oluşmaktadır. Bunlar; grup $p$ istatistiği, grup PP-istatistiği ve grup ADF-istatistiğidir.

Ayrıca çalışmada değişkenler yatay-kesit bağımlığı içerdiğinden, değişkenler arasındaki eşbütünleşme ilişkisi, yatay-kesit bağımlılığını dikkate alan ve değişkenlerin aynı seviyeden durağan olmasını gerektiren Westerlund ECM (2007) panel eşbütünleşme testi ile de araştırılmıştır. 
Eşbütünleşme ilişkisinin varlığı durumunda ise, uzun dönemli denklem tahmin edilecektir. Ardından hata düzeltme modelini (ECM) tahmin ederek kısa dönemli ilişki incelenecektir. EC modeli aşağıdaki gibi yazılabilir:

$$
\Delta Y_{1, i t}=\alpha_{1 i}+\sum_{j=1}^{p-1} \beta_{1 i j} \Delta Y_{1, i t-j}+\sum_{j=0}^{q-1} \sum_{l=2}^{k} \beta_{1 i j} \Delta X_{1, i t-j}+\mu E C T_{1, i t-1}+\varepsilon_{1 i t}
$$

(3) numaralı denklemde $\varepsilon_{\text {lit }}(I=\{1,2\})$ artık değerleri, $E C T_{1, i t-1}(I=\{1,2\})$ hata düzeltme terimini, $\mu$ uzun dönem dengesine yaklaşma hızını göstermektedir.

Son olarak seriler arasındaki nedensellik ilişkisi yatay kesit bağımlılı̆̆ını dikkate alan Dumitruscu ve Hurlin (2012) panel nedensellik testi ile analiz edilmiştir. Dumitrescu ve Hurlin panel nedensellik testinde, $x$ ve $y$ gibi iki durağan seri söz konusu olduğunda model şu şekilde yazılabilir:

$$
\begin{aligned}
& y_{i, t}=\alpha_{i}+\sum_{k=1}^{K} \gamma_{i}^{(k)} y_{i, t-k}+\sum_{k=1}^{K} \beta_{i}^{(k)} x_{i, t-k}+\varepsilon_{i, t} \\
& x_{i, t}=\delta_{i}+\sum_{k=1}^{K} \theta_{i}^{(k)} x_{i, t-k}+\sum_{k=1}^{K} \lambda_{i}^{(k)} y_{i, t-k}+\varepsilon_{i, t}
\end{aligned}
$$

Burada y mali sağlamlığı $\mathrm{x}$ ise rekabet düzeyini göstermektedir. Boş hipotez, birimler arasında nedensellik ilişkisi yoktur şeklinde oluşturulur $\left(H_{0}: \beta_{i}=0,(i=1, . ., N)\right)$.

\section{Bulgular}

Tablo 2' de ülkelere ve panel geneline ilişkin tanımlayıcı istatistikler raporlanmıştır. Ele alınan ülke grubunda 1996-2015 döneminde ortalama Lerner Endeksi 0.230, Z-skoru ise 10.84 olarak gerçekleşmiştir. Bu ülkeler içerisinde en yüksek ortalama Lerner Endeksi değerine Peru'nun, en düşük Lerner Endeksi değerine Paraguay’ın sahip olduğu görülmektedir. Buna göre ilgili dönem boyunca bankacılık sektöründe en yoğun rekabetin ortalama olarak Paraguay'da, en düşük rekabetin Peru'da gerçekleştiği söylenebilir. Z-skoru açısından ise ülkeler arasında en düşük iflas riskine sahip bankacılık sektörünün Ürdün'de, en yüksek iflas riskine sahip bankacılık

\begin{tabular}{|c|c|c|c|c|c|c|}
\hline & Ortalama & Maksimum & Minimum & Std. Hata & Çarpıklık & Basıklık \\
\hline \multirow{2}{*}{ Panel Geneli } & $\mathrm{L}: 0.230$ & L:0.495 & L:-0.629 & L: 0.116 & L:-1.617 & L: 13.56 \\
\hline & Z: 10.84 & Z: 60.43 & $Z:-2.61$ & Z: 9.97 & Z: 3.00 & Z: 13.25 \\
\hline \multirow{2}{*}{ Arjantin } & L:0.176 & L: 0.334 & L: -0.629 & L: 0.215 & L: -2.796 & L: 10.97 \\
\hline & Z: 5.434 & Z: 7.183 & Z: 2.886 & Z: 1.094 & Z: -0.393 & Z: 2.772 \\
\hline \multirow{2}{*}{ Brezilya } & L:0.226 & L:0.307 & L:0.134 & L:0.054 & L:-0.135 & L:1.870 \\
\hline & Z: 15.60 & Z: 18.283 & Z: 11.693 & Z: 2.131 & Z: -0.471 & Z: 1.858 \\
\hline \multirow[b]{2}{*}{ Şili } & L:0.199 & L:0.360 & L:0.114 & L:0.060 & L:0.784 & L:3.611 \\
\hline & Z: 7.232 & Z: 7.906 & Z: 6.187 & Z: 0.458 & Z: -0.605 & Z: 2.856 \\
\hline \multirow{2}{*}{ Kolombiya } & L:0.275 & L:0.483 & L:0.075 & L:0.121 & L:-0.051 & L:2.022 \\
\hline & Z: 5.068 & Z: 7.288 & Z: 1.825 & Z: 1.307 & Z: -1.006 & Z: 3.964 \\
\hline \multirow{2}{*}{ Hırvatistan } & L:0.265 & L:0.316 & L:0.168 & L:0.037 & L:-1.113 & L:3.780 \\
\hline & Z: 4.331 & Z: 5.193 & Z: 3.341 & Z: 0.676 & Z: -0.167 & Z: 1.516 \\
\hline \multirow{2}{*}{ Macaristan } & L:0.188 & L:0.291 & L:0.071 & L:0.064 & L:-0.288 & L:1.961 \\
\hline & Z: 5.318 & Z: 6.507 & Z: 3.909 & Z: 0.688 & Z: -0.124 & Z: 2.262 \\
\hline
\end{tabular}
sektörünün Endonezya'da olduğu ifade edilebilir.

Tablo 2: Ülkelere ve Panel Geneline Ilişskin Tanımlayıcı Istatistikler 
Eskişehir Osmangazi Üniversitesi ïBF Dergisi

\begin{tabular}{|c|c|c|c|c|c|c|}
\hline \multirow{2}{*}{ Hindistan } & L:0.234 & L:0.310 & L:0.141 & L:0.052 & L:-0.603 & $\mathrm{L}: 2.070$ \\
\hline & Z: 15.25 & Z: 18.096 & Z: 10.952 & Z: 2.283 & Z: -0.288 & Z: 1.748 \\
\hline \multirow{2}{*}{ Endonezya } & L:0.229 & L:0.387 & L:-0.384 & L:0.179 & L:-2.076 & L:7.796 \\
\hline & Z: 3.786 & Z: 5.646 & Z: -2.619 & Z: 1.784 & Z: -2.361 & Z: 9.418 \\
\hline \multirow{2}{*}{ Ürdün } & L:0.321 & L:0.436 & L:0.133 & L:0.094 & L:-0.694 & $\mathrm{L}: 2.174$ \\
\hline & Z: 43.17 & Z: 60.437 & Z: 23.752 & Z: 12.814 & Z: -0.125 & Z: 1.331 \\
\hline \multirow{2}{*}{ Litvanya } & L:0.231 & L:0.376 & L:0.037 & L:0.100 & L:-0.480 & L:2.294 \\
\hline & Z: 6.016 & Z: 7.989 & Z: 1.842 & Z: 1.442 & Z: -1.116 & Z: 4.554 \\
\hline \multirow{2}{*}{ Paraguay } & L:0.152 & L:0.279 & L:0.010 & L:0.0782 & L:-0.015 & L:2.215 \\
\hline & Z: 15.84 & Z: 20.790 & Z: 11.317 & Z: 2.172 & Z: 0.499 & Z: 3.596 \\
\hline \multirow{2}{*}{ Peru } & L:0.367 & L:0.495 & L:0.211 & L:0.107 & L:-0.295 & L:1.472 \\
\hline & Z: 14.74 & Z: 16.705 & Z: 11.913 & Z: 1.532 & Z: -0.503 & Z: 1.910 \\
\hline \multirow{2}{*}{ Polonya } & L:0.223 & L:0.347 & L:0.0007 & L:0.092 & L:-0.602 & L: 2.709 \\
\hline & Z: 7.808 & Z: 9.497 & Z: 1.574 & Z: 1.692 & Z: -2.631 & Z: 10.411 \\
\hline \multirow{2}{*}{ Romanya } & L:0.222 & L:0.325 & L:0.122 & L:0.051 & L:-0.252 & L: 2.746 \\
\hline & Z: 6.975 & Z: 11.443 & Z: 3.097 & Z: 2.464 & Z: 0.523 & Z: 2.106 \\
\hline \multirow{2}{*}{ Rusya } & L:0.194 & L:0.393 & L:0.007 & L:0.126 & L:-5.11E-05 & L: 1.585 \\
\hline & Z: 9.163 & Z: 14.794 & Z: 5.560 & Z: 2.793 & Z: 0.755 & Z: 2.341 \\
\hline \multirow{2}{*}{ Türkiye } & $\mathrm{L}: 0.184$ & L:0.310 & L:-0.038 & $\mathrm{L}: 0.084$ & L:-0.863 & L: 3.602 \\
\hline & Z: 7.753 & Z: 11.295 & Z: 0.416 & Z: 2.313 & Z: -1.531 & Z: 6.175 \\
\hline
\end{tabular}

Tabloda L; Lerner Endeksine, $Z$ ise Z-skoruna ilişkin tanımlayıcı istatistikleri ifade etmektedir.

Tablo 3'te seriler arasında yatay kesit bağımlılığı olup olmadığını belirlemek için yapılan analiz sonuçları yer almaktadır. Sonuçlar serilerde yatay kesit bağımlılı̆̆ olduğunu göstermektedir. Dolayısıyla çalışmada birinci kuşak (LLC ve IPS) birim kök testlerinin yanında ikinci kuşak Pesaran Panel birim kök (CADF) testi de kullanılmıştır.

Tablo 3: Yatay-kesit Bağımlılık Sonuçları

\begin{tabular}{lccc}
\hline Yatay-kesit Bağımlılık Testleri & Mali Sağlamlık & Rekabet & $\begin{array}{c}\text { Olasılık } \\
\text { Değeri }\end{array}$ \\
\cline { 2 - 3 } & \multicolumn{2}{c}{ ístatistik Değeri } & 0.000 \\
\hline \hline Breusch-Pagan LM & 365.2536 & 476.4339 & 0.000 \\
Pesaran scaled LM & 15.83105 & 23.00771 & 0.000 \\
Bias-corrected scaled LM & 15.41000 & 22.58665 & 0.000 \\
Pesaran CD & 11.55269 & 12.11642 & 0 \\
\hline
\end{tabular}

Tablo 4 ve Tablo 5'te ise LLC ile IPS ve CADF birim kök sonuçları sunulmuştur. Tablolar incelendiğinde serilerin seviyesinde durağan olmadıkları tespit edilmiştir. Ancak serilerin birinci farkları alındığında serilerin durağan hale geldiği belirlenmiştir.

Tablo 4: Panel Birim Kök Test Sonuçları

\begin{tabular}{lcccc}
\hline & \multicolumn{5}{c}{ Rekabet } \\
& Sabit & $\begin{array}{c}\text { Sabit } \\
\text { \& Trend }\end{array}$ & Sabit & $\begin{array}{c}\text { Sabit } \\
\text { \& Trend }\end{array}$ \\
\hline LLC & I (0) & I (0) & I (1) & $-13.6^{\mathrm{a}}$ \\
IPS & -1.23 & $-2.08^{\mathrm{b}}$ & $-13.7^{\mathrm{a}}$ & $-11.6^{\mathrm{a}}$ \\
\hline \hline & -0.63 & -0.82 & $-12.4^{\mathrm{a}}$ & $\mathrm{I}(1)$ \\
\hline LLC & & Finansal Sağlamlık & $-14.1^{\mathrm{a}}$ \\
IPS & $\mathrm{I}(0)$ & $\mathrm{I}(0)$ & $\mathrm{I}(1)$ & $-11.6^{\mathrm{a}}$
\end{tabular}

${ }^{a}$ ve $^{b}$ sırasıyla \%1 ve \%5 anlamlılık düzeyini göstermektedir. Optimal gecikme uzunluğu SIC kriterine göre belirlenmiştir. 
Tablo 5: CADF Panel Birim Kök Testi

\begin{tabular}{lccc}
\hline & t-bar & Z[t-bar] & Olasilık Değeri \\
\hline \hline Sağlamlık & -2.240 & 0.160 & 0.563 \\
$\Delta$ Sağlamlık & -3.229 & -3.758 & 0.000 \\
Rekabet & -1.385 & 3.545 & 0.999 \\
$\Delta$ Rekabet & -3.277 & -3.865 & 0.000 \\
\hline
\end{tabular}

Serilerin birinci farklarında durağan oldukları tespit edildikten sonra, Panel-PMG yaklaşımını uygulayabilmek için seriler arasında uzun dönemli ilişki olup olmadığının belirlenmesinde, Pedroni (1999) eşbütünleşme yöntemleri kullanılmıştır. Tablo 6'da Pedroni (1999) testine ilişkin elde edilen bulgular yer almaktadır.

Tablo 6: Pedroni Eşbütünleşme Testi Sonuçları

\begin{tabular}{lcc}
\hline & t-istatistiği & Olasılık Değeri \\
\hline \hline Panel v-istatistiği & 1.23 & 0.109 \\
Panel rho-istatistiği & -1.22 & 0.001 \\
Panel PP-istatistiği & -1.18 & 0.000 \\
Panel ADF-istatistiği & -1.24 & 0.000 \\
Grup rho-istatistiği & -0.91 & 0.179 \\
Grup PP-istatistiği & -3.67 & 0.000 \\
Grup ADF-istatistiği & -4.44 & 0.000
\end{tabular}

Pedroni eşbütünleşme testinde, Bartlett Kernel metodu kullanılmış ve bant genişliği Newey-West metodu ile belirlenmiştir.

Tablodan görüldüğü üzere Pedroni test sonuçlarından panel v-istatistiği haricindeki panel istatistiklerinin üçü, grup istatistiklerinden ise grup rho-istatistiği haricinde diğer istatistikler \%1 seviyesinde istatistiksel olarak anlamlı bulunmuştur. Özetle, Pedroni eşbütünleşme testinde yer alan 7 istatistikten 5 'i rekabet ile mali sağlamlık arasında eşbütünleşme ilişkisinin var olduğunu göstermektedir.

Tablo 7'de değişkenler arasındaki eşbütünleşme ilişkisini panelde yer alan serilerde yatay kesit bağımlılığını dikkate alan Westerlund (2007) ECM eşbütünleşme testi sonuçları verilmiştir. Buna göre, Ho hipotezi reddedilmiş ve paneli oluşturan bütün yatay kesit birimleri arasında eşbütünleşme ilişkisinin var olduğu kabul edilmiştir.

Tablo 7: Westerlund (2007) ECM Eşbütünleşme Testi

\begin{tabular}{ccc}
\hline istatistikler & istatistik Değeri & Bootstrap p-value \\
\hline \hline Gt & -3.820 & 0.000 \\
Ga & -12.384 & 0.172 \\
$\mathbf{P t}$ & -7.120 & 0.049 \\
$\mathbf{P a}$ & -10.955 & 0.067 \\
\hline
\end{tabular}


Seriler arasında eşbütünleşme ilişkisi tespit edildiğinden, gelişmekte olan ülke bankacılık sektörlerinde rekabet ile mali sağlamlık arasındaki ilişkiyi araştırmak için Panel ARDL-PMG tahmin yöntemine geçilmiştir.

Tablo 8'de hem PMG hem de MG tahmin yöntemine göre elde edilen sonuçlar raporlanmıştır. Hausman testi, PMG'nin MG tahminlerinden daha tutarlı olduğunu gösterdiğinden ${ }^{4}$ sadece PMG tahmin sonuçları yorumlanmıştır.

Tablo 8: PMG-MG Uzun ve Kısa Dönem Tahmin Sonuçları

\begin{tabular}{|c|c|c|c|c|}
\hline \multirow[t]{2}{*}{ Bağımlı değişken (Mali Sağlamlık) } & \multicolumn{2}{|c|}{ PMG } & \multicolumn{2}{|c|}{ MG } \\
\hline & $\begin{array}{c}\text { Uzun } \\
\text { Dönem }\end{array}$ & $\begin{array}{c}\text { Kısa } \\
\text { Dönem }\end{array}$ & $\begin{array}{c}\text { Uzun } \\
\text { Dönem }\end{array}$ & $\begin{array}{c}\text { Kısa } \\
\text { Dönem }\end{array}$ \\
\hline Lerner & $0.33^{a}$ & & 0.50 & \\
\hline $\mathrm{ECT}(-1)$ & & $-0.39^{a}$ & & $-0.42^{a}$ \\
\hline$\Delta$ Lerner & & 0.74 & & 0.79 \\
\hline c & & $1.14^{\mathrm{a}}$ & & $3.32^{\mathrm{a}}$ \\
\hline Gözlem sayısı & \multicolumn{4}{|c|}{304} \\
\hline \multicolumn{5}{|l|}{ Hausman Testi } \\
\hline $\mathrm{x} 2$ & \multicolumn{4}{|c|}{0.13} \\
\hline MG vs. PMG (Olasılık) & \multicolumn{4}{|c|}{$(0.72)$} \\
\hline DFE vs. PMG (Olasılık) & \multicolumn{4}{|c|}{$(0.66)$} \\
\hline
\end{tabular}

a\%1 anlamlılık düzeyini göstermektedir.

Tablo 8'e göre uzun dönemde Lerner endeksi ve Z-skoru arasında pozitif ve anlamlı bir ilişki olduğu gözlemlenmiştir. Bu sonuç bankacılık sektöründe rekabet artışının banka riskini arttırdığını ortaya koymaktadır. Diğer bir deyişle, rekabet ne kadar düşük olursa, banka riski de o kadar düşük olmaktadır.

Kısa dönemde de uzun dönem ile benzer şekilde seriler arasındaki kısa dönemli ilişkiyi gösteren hata düzeltme katsayısı negatif ve aynı zamanda istatistiksel olarak anlamlı bulunmuş ve rekabet ile mali sağlamlık arasında kısa dönemde ilişki olduğu sonucuna ulaşılmıştır. Aynı zamanda rekabet düzeyindeki azalışın mali sağlamlığı kısa dönemde olumlu yönde etkilediği tespit edilmiştir. Ardından ülkeler için rekabetin mali sağlamlık üzerindeki etkisi araştırılmış ve sonuçları Tablo 9'da gösterilmiştir. Buna göre sadece Arjantin için Lerner Endeksi'nin katsayısı pozitif ve istatistiksel açıdan anlamlı bulunmuştur. Böylece Arjantin bankacılık sektöründe rekabetteki artışın mali sağlamlığı kısa dönemde azalttığı söylenebilir. Diğer ülkeler için hesaplanan katsayılar ise istatistiksel açıdan anlamsız bulunmuştur.

\footnotetext{
${ }^{4}$ Buna göre uzun dönem parametreleri homojendir, bir başka ifadeyle birimden birime değişmemektedir.
} 
Tablo 9: Tahmin Edilen Kısa Dönem Katsayıları (PMG)

\begin{tabular}{llll}
\hline Bağımlı değişken (Mali Sağlamlık) & ECT(-1) & $\Delta$ Lerner & C \\
\hline \hline Arjantin & $-0.234^{\mathrm{a}}$ & $0.533^{\mathrm{b}}$ & 0.166 \\
Brezilya & $-0.272^{\mathrm{a}}$ & 0.528 & 0.377 \\
Şili & -0.031 & 0.900 & 1.110 \\
Türkiye & $-0.778^{\mathrm{a}}$ & 0.802 & 1.893 \\
Kolombiya & $-0.429^{\mathrm{a}}$ & 1.240 & 1.622 \\
Hırvatistan & $-0.406^{\mathrm{a}}$ & 1.158 & 0.940 \\
Macaristan & $-0.558^{\mathrm{a}}$ & 1.559 & 1.269 \\
Hindistan & $-0.321^{\mathrm{a}}$ & 2.290 & 1.186 \\
Endonezya & $-0.326^{\mathrm{a}}$ & -0.338 & 1.082 \\
Ürdün & $-0.161^{\mathrm{a}}$ & 0.338 & 0.736 \\
Litvanya & $-0.362^{\mathrm{a}}$ & 1.855 & 0.609 \\
Paraguay & $-0.230^{\mathrm{a}}$ & 1.106 & 1.638 \\
Peru & $-0.185^{\mathrm{a}}$ & -0.017 & 0.199 \\
Polonya & $-0.550^{\mathrm{a}}$ & 2.946 & 0.799 \\
Romanya & $-0.345^{\mathrm{a}}$ & 1.385 & 1.675 \\
Rusya & $-0.196^{\mathrm{a}}$ & 2.796 & 0.934 \\
\hline
\end{tabular}

${ }^{a}$ ve ${ }^{b}$ sırasıyla $\% 1$ ve $\% 5$ anlamlılık düzeyini göstermektedir.

Uzun dönem dengesine yaklaşma hızı açısından ise ECT(-1) katsayısı Şili hariç, diğer 15 ülke için istatistiksel açıdan anlamlı ve 0 ile -1 arasında hesaplanmıştır. Bu durum hata düzeltme mekanizmasının çalıştığını ve bir dönemde meydana gelen sapmaların sonraki dönemde ya da dönemlerde düzelebileceğini ortaya koymaktadır. Buna göre, bir dönemde oluşan dengesizliğin en kısa sürede düzeltilip uzun dönem dengesine yaklaşması ülke olarak \% 77.8 ile Türkiye olarak belirlenmiştir. Türkiye'yi sırasıyla \%55.8 ile Macaristan, \%55 ile Polonya, \%42.9 ile Kolombiya, \%40.6 ile Hırvatistan, \%36 ile Litvanya, \%34 ile Romanya, \%32.6 ile Endonezya, \%32 ile Hindistan, \%27.2 ile Brezilya, \%23.4 ile Arjantin, \%23 ile Paraguay, \%19.6 ile Rusya, \%18.5 ile Peru ve son olarak \%16.1 ile Ürdün izlemektedir.

Son olarak rekabet ile mali sağlamlık arasındaki nedensellik ilişkisi yatay-kesit bağımlılığını dikkate alan Dumitruscu ve Hurlin (2012) panel nedensellik testi ile analiz edilmiş ve sonuçları Tablo 10 'da sunulmuştur. Tabloya göre rekabetten mali sağlamlığa doğru tek yönlü bir nedensellik söz konusu olduğu belirlenmiştir.

Tablo 10: Dumitruscu ve Hurlin (2012) Panel Nedensellik Testi

\begin{tabular}{lccc}
\hline Boş Hipotez & W-Stat & Zbar-Stat & p-değeri \\
\hline \hline$\Delta$ Sağlamlık $\Delta$ Rekabetin nedeni değildir & 2.76791 & 0.56925 & 0.5692 \\
$\Delta$ Rekabet $\Delta$ Sağlamlığın nedeni değildir & 7.99332 & 7.92707 & 0.002 \\
\hline
\end{tabular}




\section{Sonuç}

Ekonomik gelişmeye katkı sağlayan bankacılık sektöründe rekabet konusu, sektörün kredinin tahsis edilmesinde kritik rol oynaması nedeniyle son yıllarda büyük ilgi görmektedir. Bu çalışmada 1996-2015 dönemi için Panel ARDL-PMG yaklaşımı kullanılarak gelişmekte olan ülkelerde bankacılık rekabeti ile mali sağlamlık arasındaki kısa ve uzun dönemli ilişki araştırılmıştır. Bu amaçla piyasadaki rekabet düzeyi ölçümü için Lerner endeksi ve banka riski ölçümü için ise Z-skoru kullanılmıştır. Arjantin, Brezilya, Şili, Türkiye, Kolombiya, Hırvatistan, Macaristan, Hindistan, Endonezya, Ürdün, Litvanya, Paraguay, Peru, Polonya, Romanya ve Rusya'da faaliyette bulunan bankalara ilişkin yapılan analiz sonuçları rekabet ile mali sağlamlık arasında hem kısa hem de uzun dönemde negatif ilişki olduğunu göstermiştir. Buna göre yüksek banka rekabetinin banka riskini arttırdığı ve gelişmekte olan ülkelerde bankacılık sektörünün istikrarına zarar verebileceği söylenebilir. Elde edilen sonuçlar Demsetz vd. (1996); Salas ve Saurina (2003); Yeyati ve Micco (2007); Tunay (2009); Turk (2010); Yağcılar (2011); Fu vd. (2014); Taşkın (2014); Cuestas vd. (2017); Leroy ve Lucotte (2017); Kouki ve Al-Nasser (2017) ile örtüşmektedir. Sonuç olarak, bulgular "rekabet-kırılganlık" görüşünü destekler niteliktedir. Buna göre artan rekabet bankaların piyasa gücünü aşındırmakta, karlılıklarını azaltmakta, banka değerlerini düşürmekte ve banka risklerini arttırmaktadır. Nedensellik testi sonuçları ise rekabetin mali sağlamlığın nedeni olduğunu göstermiştir.

Düzenleyici ve denetleyici kurumlar açısından, böyle bir durumun varlığı bu ülkelerde bankacılık sektörü yapısının gelecekteki gelişiminin kritik bir öneme sahip olduğunu ortaya koymaktadır. Bu sonuçlar doğrultusunda bu ülkelerde bankacılık sektörünün izlenmesi ve düzenlenmesi ile ilgili politika yapıcılar, bankaların iflas riskini önleyecek bazı reformları tercih edebilirler. Örneğin borç verme mekanizmalarında daha uygun bir risk yönetiminin benimsenmesi, karlılıkların arttırılması veya muhafaza edilmesinde aşırı ve riskli kredi genişlemelerinin önlenmesi gibi düzenlemeler yapılabilir. Ayrıca politika yapıcıların fazla rekabetin bankacılık istikrarsızlığıyla sonuçlanabileceğini göz önünde bulundurmaları, birleşme ve devralmaların bankacılık sektörü yapısı üzerindeki etkilerini değerlendirirken piyasa gücü ve banka riski arasındaki güçlü etkileşimi akılda tutmaları gerekmektedir. Böylece politika yapıcılar küçük ölçekli bankaların piyasada faaliyetlerini devam ettirme olanaklarını artırmak için bankalar arasında birleşme ve satın alma faaliyetlerini de teşvik edebilir. 


\section{Kaynaklar}

Abbasoğlu, Osman; Furkan, Ahmet; Faruk, Aysan; Güneş, Ali (2007), “Concentration, Competition, Efficiency and Profitability of the Turkish Banking Sector in the Post-Crisis Period", MPRA Working Paper, No. 5494: 1-23.

Ağırman, Ensar; Özcan, Muhammet; Yılmaz, Ömer (2014), "Terörizmin Finansal Piyasalara Etkisi: Ampirik Bir Çalışma”, BDDK Bankacılık ve Finansal Piyasalar, Cilt. 8, Sayı. 2: 99-117.

Angelini, Paolo; Cetorelli, Nicola (1999), "Bank Competition and Regulatory Reform, The Case of The Italian Banking Industry", Working Paper, No. 380: 1-47.

Apergis, Nicholas; Polemis, L. Michael (2016), "Competition and Efficiency in the MENA Banking Region: A NonStructural DEA Approach”, Applied Economics, Vol. 48, No. 54: 5276-5291.

Apriadi, Intan; Sembel, Roy; Santosa, Perdana, Wahyu; Firdaus, Muhammad (2016), "Banking Fragility in Indonesia: A Panel Vector Autoregression Approach", IJABER, Vol. 14, No. 14: 1193-1224.

Arrawatia, Rakesh; Misra, Arun; Dawar, Varun (2015), "Bank Competition and Efficiency: Empirical Evidence from Indian Market", International Journal of Law and Management, Vol. 57, No. 3: 217-231.

Asongu, Simplice; Ghassen, El Montasser; Hassen, Toumi (2016), "Testing the Relationships between Energy Consumption, CO2 Emissions, and Economic Growth in 24 African Countries: A Panel ARDL Approach", Environmental Science and Pollution Research, Vol. 23, No.7: 6563-6573.

Baltagi, Badi H; Feng, Qu; Kao, Chihwa (2012), "A Lagrange Multiplier Test for Cross-Sectional Dependence in a Fixed Effects Panel Data Model”, Journal of the Econometrics, Vol. 170: 164-177.

Beck, Thorsten; Olivier De Jonghe; Schepens, Glenn (2013), "Bank Competition and Stability: Cross-Country Heterogeneity", Journal of Financial Intermediation, Vol. 22, No. 2: 218-244.

Berger, N. Allen; De Young, Robert (1997), "Problem Loans and Cost Efficiency in Commercial Banks”, Journal of Banking and Finance, Vol. 21: 849-870.

Berger, Allen, N.; Hannan, Timothy (1998), "The Efficiency Cost of Market Power in the Banking Industry: A Test of the "Quiet Life" and Related Hypotheses", The Review of Economics and Statistics, Vol. 80, No. 3: 454-465.

Berger, Allen N.; Leora, F. Klapper; Turk-Ariss, Rima (2009), "Bank Competition and Financial Stability", Journal of Financial Services Research, Vol. 35, No. 2: 99-118.

Besanko, David; Thakor, Anjan (1993), "Relationship Banking, Deposit Insurance and Bank Portfolio Choice", in Capital Markets and Financial Intermediation: Cambridge University Press: 1-27.

Bildirici, Melike, Elif; Kayıkçı, Fazıl (2013), "Effects of Oil Production on Economic Growth in Eurasian Countries: Panel ARDL Approach", Energy, Vol. 49: 156-161.

Bofondi, Marcello; Gobbi, Giorgio (2004), "Bad Loans and Entry into Local Credit Markets", Bank of Italy Temi di Discussione del Servizio Studi, No. 509: 1-49.

Boubaker, Sabri; Jouini, Jamel (2014), “Linkages between Emerging and Developed Equity Markets: Empirical Evidence in the PMG Framework", The North American Journal of Economics and Finance, Vol. 29: 322-335.

Boyd, John, H.; De Nicoló, Gianni (2005), "The Theory of Bank Risk Taking and Competition Revisited”, The Journal of Finance, Vol. 60, No. 3: 1329-1343.

Breusch, Trevor; Pagan, Adrian (1980), "The Lagrange Multiplier Test and its Application to Model Specification in Econometrics", Review of Economic Studies, Vol. 47: 239-253.

Casu, Barbara; Girardone, Claudia (2009), "Testing the Relationship between Competition and Efficiency in Banking: A Panel Data Analysis", Economics Letters, Vol. 105, No. 1: 134-137.

Chen, Xiaofen (2007), “Banking Deregulation and Credit Risk: Evidence from the EU”, Journal of Financial Stability, Vol. 2: 356-390.

Chirwa, Themba, G. (2018), "The Determinants of Public Debt in the Euro Area: A Panel ARDL Approach", UNISA Working Paper: 1-34.

Cuestas, Juan Carlos, Yannick, Lucotte; Reigl, Nicolas (2017), "Banking Sector Concentration, Competition and Financial Stability: The Case of the Baltic Countries", Bank of Estonia Working Paper, No. wp2017-7: 1-53.

Demirguc-Kunt, Asli; Enrica, Detragiache; Tressel, Thierry (2006), "Banking on the Principles: Compliance with Basel Core Principles and Bank Soundness", IMF Working Paper, No. WP/06/242: 1-47.

Demsetz, Harold (1973), "Industry Structure, Market Rivalry, and Public Policy", Journal of Law and Economics, Vol. 16: 1-9. 


\section{Eskişehir Osmangazi Üniversitesi IïB Dergisi}

Demsetz, Rebecca; Saidenberg, Marc; Strahan, Philip (1996), “Banks with Something to Lose: The Disciplinary Role of Franchise Value", FRBNY Economic Policy Review October, 1-14.

Dima, Bogdan, Marius Sorin Dincă; Spulbăr, Cristi (2014), "Financial Nexus: Efficiency and Soundness in Banking and Capital Markets", Journal of International Money and Finance, Vol. 47: 100-124.

Dumitrescu, Elena-Ivona; Hurlin, Chrristophe (2012), "Testing for Granger Non-Causality in Heterogeneous Panels", Economic Modelling, Vol. 29, No. 4: 1450-1460.

Fu, Xiaoqing Maggie; Yongjia, Rebecca, Lin; Molyneux, Philip (2014), “Bank Competition and Financial Stability in Asia Pacific", Journal of Banking \& Finance, Vol. 38: 64-77.

Hausman, Jerry (1978), "Specification Tests in Econometrics", Econometrica, Vol. 46: 1251-1271.

http://www.worldbank.org/en/publication/gfdr/data/global-financial-development-database, (Erişim: 02.04.2018).

Im, Kyung So; Pesaran, M. Hashem; Shin, Yongcheol (2003), "Testing for Unit Roots in Heterogeneous Panels", Journal of Econometrics, Vol. 115: 53-74.

İskenderoğlu, Ömer; Tomak, Serpil (2013), “Competition and Stability: An Analysis of the Turkish Banking System”, International Journal of Economics and Financial, Vol. 3, No. 3: 752-762.

Jimenez, Gabriel; Lopez, Jose; Saurina, Jesus (2013), “How Does Competition Affect Bank Risk-taking?”, Journal of Financial Stability, Vol. 9, No. 2: 185-195.

Kasman, Adnan; Kasman, Saadet (2016), "Bank Size, Competition and Risk in the Turkish Banking Industry", Empirica, Vol. 43, No. 3: 607-631.

Keeley, Michael (1990), "Deposit Insurance, Risk and Market Power in Banking”, American Economic Review, Vol. 80: 1183-1200.

Korkmaz, Özge; Erer, Deniz; Erer, Elif (2016), “Bankacılık Sektöründe Yoğunlaşma İle Finansal Kırılganlık Arasındaki illişki: Türkiye Örneği (2007-2014)”, Journal of Accounting \& Finance, Cilt. 69: 127-146.

Kouki, Imen; Al-Nasser, Amjad (2017), "The Implication of Banking Competition: Evidence from African Countries", Research in International Business and Finance, Vol. 39, Part B: 878- 895.

Kwan, Simon; Eisenbeis, Robert (1997), "Bank Risk, Capitalization, and Operating Efficiency", Journal of Financial Services Research, Vol. 12: 117-131.

Leroy, Aurélien; Lucotte, Yannick (2017), “Is There a Competition-Stability Trade-Off in European Banking?”, Journal of International Financial Markets, Institutions and Money, Vol. 46: 199-215.

Levin, Andrew; Chien-Fu Lin; Chu, Chia-Shang James (2002), "Unit Root Tests in Panel Data: Asymptotic and FiniteSample Properties", Journal of Econometrics, Vol. 108: 1-24.

Maudos, Joaquín; De Guevara, Juan Fernandez (2004), "Factors Explaining the Interest Margin in the Banking Sectors of the European Union", Journal of Banking \& Finance, Vol. 28, No. 9: 2259-2281.

Mercieca, Steve; Schaeck, Klaus; Wolfe, Simon (2007), “Small Banks in Europe: Benefits from Diversification?”, Journal of Banking and Finance, Vol. 31: 1975-1998.

Özcan, Abdulvahap; Çiftçi, Cemil (2015), “Türkiye'de Mevduat Bankacılığında Yoğunlaşma ve Kârlılık ilişkisi (2006-2013 Dönemi)”, Ömer Halisdemir Üniversitesi İktisadi ve İdari Bilimler Fakültesi Dergisi, Cilt. 8, Sayı. 3: 1-12.

Padoa-Schioppa, Teo (2001), “Competition and Supervision in the Banking Industry: A Changing Paradigm?”, European Finance Review, Vol. 5: 1-5.

Pagano, Marco (1993), “Financial Markets and Growth: An Overview”, European Economic Review, Vol. 37: 613-622.

Pedroni, Peter (1999), "Critical Values for Cointegration Tests in Heterogeneous Panels with Multiple Regressors", Oxford Bulletin of Economic Statistics, Vol. 61: 653-670.

Pesaran, M. Hashem; Shin, Yongcheol; Smith, Ron (1999), “Pooled Mean Group Estimation of Dynamic Heterogeneous Panels", Journal of the American Statistical Association, Vol. 94, No. 446: 621-634.

Pesaran, M. Hashem (2004), General Diagnostic Tests for Cross Section Dependence in Panels. University of Cambridge, Faculty of Economics, Cambridge Working Papers in Economics No. 0435.

Pesaran, M. Hashem (2007), "A Simple Panel Unit Root Test in the Presence of Cross-Section Dependence”, Journal of Applied Econometrics, Vol. 22, No. 2: 265-312.

Petersen, Mitchell; Rajan, Raghuram (1995), "The Effect of Credit Market Competition on Lending Relationships", The Quarterly Journal of Economics, Vol. 110: 407-443. 
Beighley, H. Prescott; McCall; S. Alan (1975), "Market Power and Structure and Commercial Bank Installment Lending”, Journal of Money, Credit, and Banking, Vol. 7, No. 4: 449-467.

Repullo, Rafael (2004), “Capital Requirements, Market Power, and Risk-Taking in Banking”, Journal of Financial Intermediation, Vol. 13: 156-182.

Salas, Vicente; Saurina, Jesus (2003), "Deregulation, Market Power and Risk Behavior in Spanish Banks", European Economic Review, Vol. 47: 1061-1075.

Schaeck, Klaus; Cihák, Martin (2008), "How Does Competition Affect Efficiency and Soundness in Banking? New Empirical Evidence", European Central Bank Working Paper, No. 932: 1-46.

Schaeck, Klaus; Martin, Cihák; Wolfe, Simon (2006), “Are More Competitive Banking Systems More Stable?”, IMF Working Paper, No. WP/06/143: 1-37.

Shaffer, Sherril (1993), "A Test of Competition in Canadian Banking", Journal of Money, Credit, and Banking, Vol. 25: 49-61.

Taşkın, Dilvin (2014), "Türk Bankacılık Sektöründe Finansal İstikrar-Rekabet İlişkisi”, Maliye Finans Yazıları, Cilt. 103: 175-204.

Tunay, Batu (2009), “Türk Bankacılık Sektöründe Rekabet ve Kırılganlık”, Bankacılar Dergisi, Cilt. 68: 30-56.

Turk, Rima (2010), “On the Implications of Market Power in Banking: Evidence from Developing Countries", Journal of Banking \& Finance, Vol. 34, No. 4: 765-777.

Westerlund, Joakim (2007), "Testing for Error Correction in Panel Data", Oxford Bulletin of Economics and Statistics, Vol. 69, No. 6: 709-748.

Wheelock, David, C.; Wilson, W. Paul (1995), "Explaining Bank Failures: Deposit Insurance, Regulation, and Efficiency”, Review of Economics and Statistics, Vol. 77: 689-700.

Williams, Jonathan (2004), "Determining Management Behaviour in European Banking", Journal of Banking and Finance, Vol. 28: 2427-2460.

Yağcılar, Gamza, Göçmen (2011), Türk Bankacılık Sektörünün Rekabet Yapısının Analizi, Ankara: BDDK Kitapları.

Yaldız, Elmas; Bazzana, Flavio (2010), "The Effect of Market Power on Bank Risk Taking in Turkey", Financial Theory and Practice, Vol. 34, No. 3: 297-314.

Yeyati, Eduardo Levy; Micco, Alejandro (2007), "Concentration and Foreign Penetration in Latin American Banking Sectors: Impact on Competition and Risk", Journal of Banking and Finance, Vol. 31: 1633-1647. 
Eskişehir Osmangazi Üniversitesi IißBF Dergisi 